\title{
Modelling river constituent budgets in the Burnett Mary region, Queensland, Australia: An example of how it could be used in prioritising management actions
}

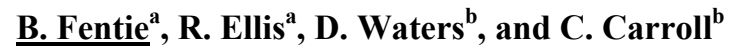 \\ ${ }^{a}$ Department of Science Information Technology, Innovation and Arts \\ ${ }^{b}$ Department of Natural Resources and Mines \\ Email: banti.fentie@science.dsitia.qld.gov.au
}

\begin{abstract}
To improve the declining water quality entering the Great Barrier Reef (GBR), the Australian and Queensland governments are funding changes to on-ground management practices through the Reef Plan Program. Reef Plan 2013, outlines specific water quality targets to address the decline in water quality entering the GBR. For example, it has set a target of $20 \%$ reduction in fine sediment export by 2018. An integrated water quality monitoring and modelling program has been established to measure and report on progress in meeting the water quality targets. Current prioritisation of on-ground management actions are based on previous modelling outputs, local knowledge and perception of areas and industries that are likely to generate disproportionately high amounts of constituents. The current Catchment modelling approach will enable more effective prioritisation to catchment areas and pollutant generation processes. This paper reports the results of the recent modelling of constituent budgets using the Source Catchments model outputs including identification of sources of supply to the river system, sinks and contributions to export to the GBR from catchments in the Burnett Mary region, and discusses how this information can be used in prioritizing on-ground management actions. This paper also highlights how examination of modelled constituent budgets can be used to (1) identify parts of the model that may be improved and (2) provide insight into the selection of water quality monitoring sites for model calibration and validation.
\end{abstract}

Of the total modelled suspended sediment (TSS) supplied to the stream network, only $37 \%$ (438 kt) is exported, $46 \%(541 \mathrm{kt} / \mathrm{y})$ is trapped in reservoirs (estimated by an algorithm used commonly elsewhere but modified to simulate daily sediment trapping in the Burdekin Falls Dam), 17\% (198 kt/y) is lost as the result of water extraction while floodplain deposition and residual storage accounted for only $1 \%$. The model estimates that streambank erosion, hillslope erosion and gully erosion contribute 56,28 , and $6 \%$ of the TSS exported to the GBR lagoon; with each respective erosion process supplying 29,27 , and $3 \%$ of particulate nitrogen $(\mathrm{PN})$, and 28,33 , and $3 \%$, of particulate phosphorus (PP).

Particulate Nitrogen and Phosphorus budgets were similar to the TSS percent exported compared to the total amount generated. On the other hand, the model estimates that higher percentages of dissolved nutrients and Photosystem II inhibiting herbicides (PSII) that are supplied to the stream network (i.e., $68 \%$ dissolved inorganic nitrogen (DIN), 67\% dissolved organic nitrogen (DON), 67\% dissolved organic phosphorus (DOP) and $65 \%$ dissolved inorganic phosphorus (DIP) and 67\% PSII inhibitor herbicides) are exported to the GBR lagoon.

Having the functionality in the model to identify the specific pollutant sources and generation processes that contribute comparatively high constituent export to the GBR lagoon, will help to maximise progress towards water quality targets. For example, model results show that streambank erosion in the Mary catchment is identified to be contributing the highest proportion of TSS of all GBR catchments. Therefore, streambank erosion reduction through riparian revegetation and fencing off to restrict stock access may be considered to be management actions of priority in this catchment. In summary, the GBR Source Catchments modelling framework has now been developed with a range of enhancements not available in previous modelling programs. The development of the dynamic SedNet Source modelling functionality provides regional NRM groups with valuable information for prioritisation of on-ground management investment.

Keywords: Burnett Mary, constituent budget, Great Barrier Reef, water quality 


\section{INTRODUCTION}

Great Barrier Reef (GBR) catchments have been extensively modified for agricultural production and urbanisation since European settlement leading to a decline in water quality entering the GBR lagoon (Brodie et al., 2013). In response to these water quality concerns, the Reef Water Quality Protection Plan 2003 (Anon, 2003) was initiated and updated in 2009 through a joint Queensland and Australian government initiative (Department of Premiers and Cabinet, 2009) with a further update in 2013 (Department of Premiers and Cabinet, 2013). A clear set of water quality and management practice targets are outlined for catchments discharging to the GBR, with the long-term goal to ensure that the quality of water entering the Reef has no detrimental impact on the health and resilience of the Reef. A key aspect of the initiative is the Paddock to Reef Integrated Monitoring, Modelling and Reporting (P2R) Program (Waterhouse et al., 2012); (Carroll et al., 2012). This program has been established to measure and report on progress towards the targets outlined in the Reef Plan. It combines monitoring and modelling at paddock through to catchment and reef scales.

Modelling provides a means of extrapolating monitoring data through time and space and provides an opportunity to explore the climate and management interactions and their associated impacts on water quality. The catchment modelling used in this study combines information on the adoption of improved management practices and paddock modelling to predict impacts of those management practice improvements on reductions in loads of fine sediment, nutrients (species of nitrogen and phosphorus) and photosystem II inhibiting herbicides (PSII) entering the GBR lagoon. Monitoring data are the most important point of truth for model validation and parameterisation. Combining modelling and monitoring ensures continual improvement in the models while at the same time identifying data gaps and priorities for future monitoring.

Previous water quality modelling studies in the Burnett Mary region include DeRose et al. (2002), (Fentie et al., 2006) and (Fentie et al., 2009). These studies used the SedNet model (Wilkinson et al., 2004) which is a long-term annual average model with fewer constituent budget elements than in Source Catchments framework (eWater Cooperative Research Centre, 2010) used in this study. Fentie et al. (2009) compared the spatial pattern of fine sediment generation and supply estimated by the SedNet model with that modelled using a predecessor of the Source Catchments modelling framework (E2). Whilst the above studies were based on the best available knowledge and input data at the time, the Source Catchments modelling framework is a much more flexible modelling framework that allows the extension of its functionality via the use of purpose built model plug-ins to meet specific modelling objective. The use of a daily time step model enabled the interaction of climate and management to be expressed in the model and the incorporation of SedNet functionality was included to enable representation of generation and transport processes such as gully and streambank erosion and floodplain deposition, all important processes across the GBR.

In addition fit for purpose paddock scale model outputs were coupled to Source catchments for specific agricultural industries (land uses). The additional functionality was essential to meet the Reef Plan objectives namely to assess progress towards water quality targets.

Reporting on the sources, sinks and the quantity of each of pollutant exported facilitates:

- Identification of management practices and budget elements that can result in maximum water quality improvements and hence facilitates prioritisation of on-ground management actions;

- Selection of water quality monitoring sites which can then be used for model calibration and validation;

- Comparison with available monitoring data to identify parts of the model that may be improved and/or modified.

Good progress towards the Reefplan targets has been achieved already in the short period of the program. Model results have shown that investment in on-ground management actions in the Burnett Mary region so far have resulted in TSS, TN and TP export load reductions of 3\%, 5\%, and 8\%, respectively. However, by utilising the latest modelling results prioritisation of management actions would be even more effective targeting catchment areas and pollutant generation processes contributing the highest proportion of pollutants to the GBR. The objective of this paper is to demonstrate how constituent budget modelling can be used to prioritise on-ground management actions in the Burnett Mary region, Queensland, Australia in order to maximize reduction in constituent export. 


\section{METHODS}

\subsection{The Burnett Mary region}

The Burnett Mary Natural Resources Management (NRM) Planning Region (Figure 1) includes coastal catchments south of the Fitzroy Catchment to the Noosa River, including the RAMSAR listed Great Sandy Straits and the Fraser Island World Heritage Area. The region experiences a typically humid subtropical climate. Rainfall in the NRM region varies from less than 1200 $\mathrm{mm} /$ year in the semi-arid Burnett River Headwaters to $1200-1800 \mathrm{~mm} /$ year in the humid coastal strip and Mary River. Land use patterns strongly follow variations in soils and rainfall across the Burnett Mary NRM region. At the regional scale, land uses are structured as a gradient between nature conservation and minimal use (more dominantly in the Mary) to grazing (more dominantly in the Burnett). Irrigated cropping and dryland cropping also predominate in the Burnett, in contrast to fruit and vegetable produce, rural residential, pine forestry, and dairy in the Mary.

\subsection{Source Catchments model structure and the Dynamic SedNet plug-in}

A Source Catchments model is built upon a network of sub-catchments, links and nodes. A sub-catchment is further delineated into 'Functional Units' (FUs) based on common hydrology response or behavior (eWater Cooperative Research Centre, 2010). In the case of the

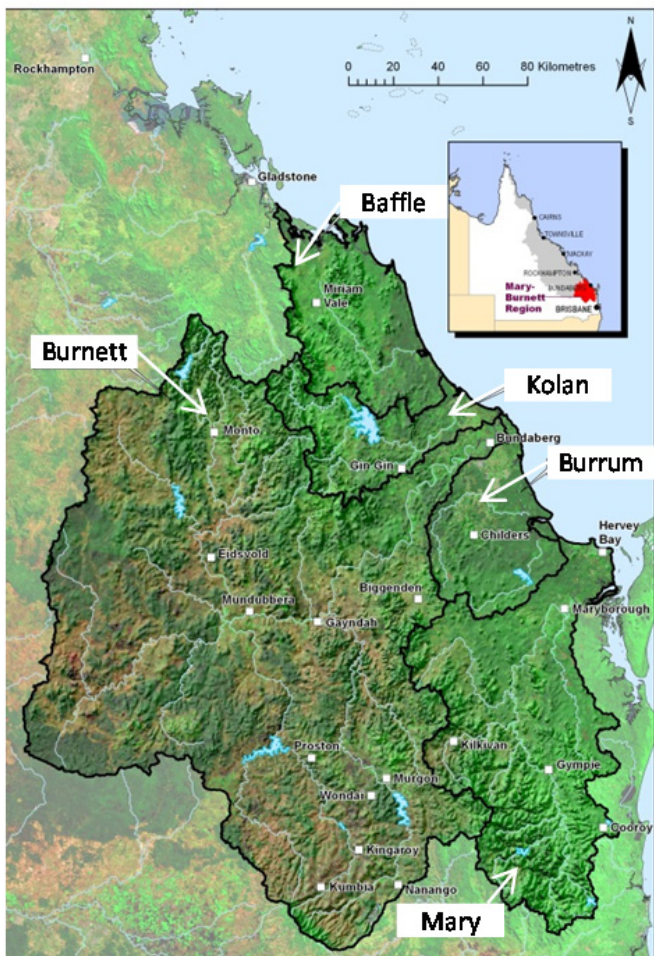

Figure 1. Location of the Burnett Mary region GBR Source Catchments Framework, FUs were defined as land use categories based the 2009 Queensland Land use Mapping Program (DSITIA, 2012) land use map of the region. Nodes and links represent the stream network and runoff and constituents are routed from a sub-catchment through the stream network via nodes and links.

\subsubsection{Hydrology}

For runoff generation, the SIMHYD rainfall runoff model (eWater Cooperative Research Centre, 2010) was selected as it has relatively few parameters and it has previously been proven to provide adequate estimate of runoff in the GBR (Ellis et al., 2009). Each FU possesses a unique instance of the SIMHYD rainfall-runoff, and constituent generation models (Chiew et al., 2002). Nodes represent stream confluences, features such as gauging stations and dams, and sub-catchment outlets. Components of the water budget such as extractions to meet water demands are modelled at nodes. Constituent losses associated with water extractions are calculated and included in the constituent budget. Links connect nodes, and represent streams. A range of models can be applied to links to route or process water and constituents throughout the network (Accad et al., 2001).

\subsubsection{Constituent Generation: Components of the constituent budget in the Dynamic SedNet plug-in}

Constituent generation is estimated using a range of component models. The most fit for purpose model that could adequately represent the processes of interest was used for each generation component. The dynamic SedNet plug-in is developed asa custom built plug-in incorporating a range of constituent generation modelling functionality required meeting the modelling objectives of Reef Plan. The APSIM (Agricultural Production Systems Simulator (Keating et al., 2003) was chosen for modelling constituent generation from sugarcane land use, particularly for dissolved inorganic nitrogen in runoff and deep drainage. The Howleaky? (Rattray et al., 2004) model, with some enhancements, was used to model pesticides and phosphorus in sugarcane and for all constituents for cropping (Shaw et al., 2012). The Revised Soil Loss Equation (RUSLE) is used to model the generation of TSS and particulate nutrients from grazing land use.

Figure 2 depicts a conceptual representation of the constituent budget in the Dynamic SedNet plugin. The sources of constituents represented in the model are: Hillslope erosion, Gully erosion (spatial input into the 
model as gully density), Streambank erosion, Point Source, Diffuse Dissolved, and Event Mean Concentration/Dry Whether Concentration (EMC/DWC). For TSS and particulate nutrients, land uses modelled using EMC/DWC values include nature conservation, forestry, urban and horticulture. Constituent sinks in the model are: Extraction, Flood Plain Deposition, Reservoir Deposition, Reservoir Decay, Residual Link Storage, Stream Decay and Stream Deposition.

Ellis and Searle (2013) provide a detailed description of each component of the constituent budget. Components of the constituent budget are categorised into "Source" (supply to stream network), "Sink" (losses), "Export" (to GBR) and "Other" (amount still in transport which is referred to as residual link storage). All components of each of the four categories are

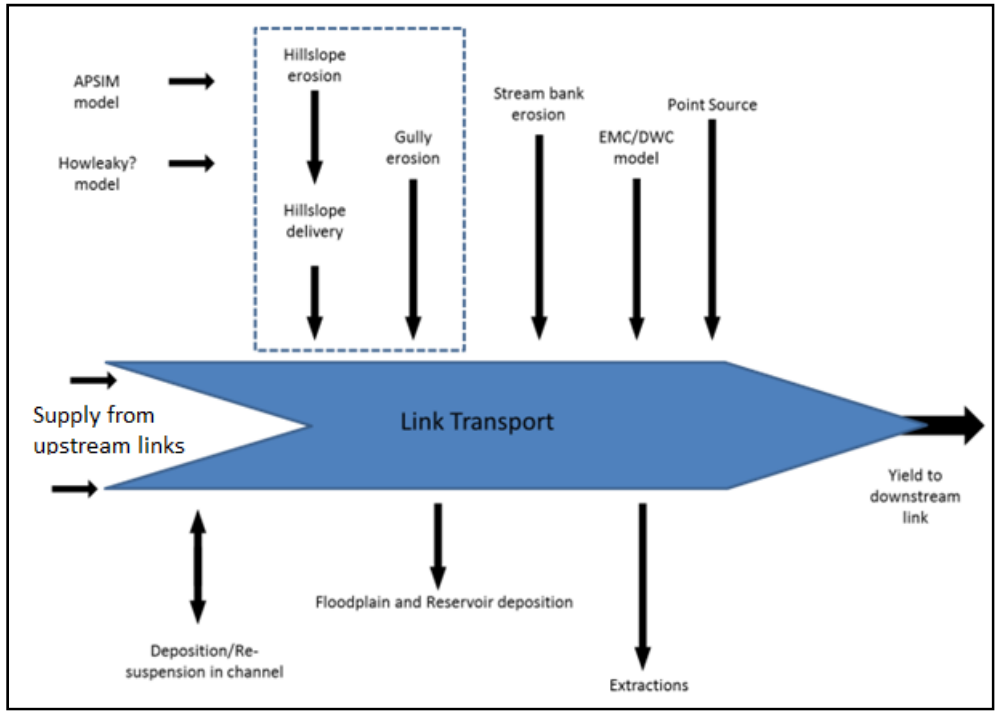

Figure 2. Conceptual representation of the constituent budget summed up to give the total for the category. For example the sum of hillslope, gully, streambank, point sources, undefined and diffuse dissolved under the "Source" gives the total for this category for each constituent. Similarly, the sum of these components under the "Export" category gives the total export from each constituent. The constituent budget identifies components (sources) that contribute higher constituent export than others. Modelling of the constituent budget of natural (pre-European) scenario would then allow us to determine the contribution of sources to the anthropogenic load as the difference between the current load and the natural load. The above results are then validated against local knowledge and available data before a map showing the spatial pattern of the extent of the contribution from this major source is produced and used to prioritise locations of on-ground investment on management practice changes to maximize the reduction in constituent export. The average annual constituent budget presented here covers a modelling period of 23 years (1986-2009).

\section{RESULTS AND DISCUSSION}

Table 1 summarises the constituent budget with the contribution of each budget element categorized into Source (supply to stream network), Sink (losses),

Table 1. Average Annual constituent budget of the Burnett Mary region for the modelling period (1986-2009)

\begin{tabular}{|c|c|c|c|c|}
\hline Budget element & $\begin{array}{l}\text { TSS } \\
(\mathrm{kt} / \mathrm{y})\end{array}$ & $\begin{array}{l}\text { TN } \\
(t / y)\end{array}$ & $\begin{array}{l}\text { TP } \\
(\mathrm{t} / \mathrm{y})\end{array}$ & $\begin{array}{l}\text { PSII } \\
(\mathrm{kg} / \mathrm{y})\end{array}$ \\
\hline Sources & 1190 & 3780 & 817 & 2333 \\
\hline Hillslope & 453 & 594 & 254 & \\
\hline Gully & 201 & 116 & 45 & \\
\hline Streambank & 462 & 395 & 133 & \\
\hline Point Source & & 84 & 23 & \\
\hline Diffuse Dissolved & & 1373 & 94 & \\
\hline Undefined & 74 & 1219 & 267 & 2333 \\
\hline Sinks & 748 & 1370 & 377 & 778 \\
\hline Extraction & 198 & 1345 & 361 & 574 \\
\hline Flood Plain Deposition & 9 & 10 & 5 & \\
\hline Reservoir Deposition & 541 & 15 & 11 & \\
\hline \multicolumn{5}{|l|}{ Reservoir Decay } \\
\hline Stream Decay & & & & 204 \\
\hline \multicolumn{5}{|l|}{ Stream Deposition } \\
\hline Export & 438 & 2388 & 435 & 1552 \\
\hline Hillslope & 121 & 261 & 104 & \\
\hline Gully & 28 & 31 & 10 & \\
\hline Streambank & 243 & 278 & 86 & \\
\hline Point Source & 0 & 73 & 21 & \\
\hline Diffuse Dissolved & 0 & 826 & 51 & \\
\hline EMC/DWC & 47 & 919 & 163 & 1552 \\
\hline Other & 4 & 23 & 4 & 5 \\
\hline Residual Link Storage & 4 & 23 & 4 & 5 \\
\hline
\end{tabular}
Export (to GBR) and Other (amount still in transport which is referred to as residual link storage). Where a constituent for a particular budget element is not modelled as part of a budget element, values are left blank.

Of the TSS supplied to the stream network, $46 \%(541 \mathrm{kt} / \mathrm{y})$ is trapped in reservoirs, $17 \%$ is lost as the result of water extraction while floodplain deposition and residual storage together accounted for $1 \%$ of the sediment budget. Loss associated with water extraction is the main budget element for constituents other than TSS, accounting for $32 \%$ of DIN, 32\% of DON, 33\% of DOP, 33\% of DIP and $25 \%$ of PSII budget, respectively. The model estimates indicate that of the $1190 \mathrm{kt}$ of TSS supplied to the stream network on an average annual basis, only $37 \%$ (438 kt) is exported to the reef with the remaining $63 \%$ ( $751 \mathrm{kt})$ deposited within the catchments as the result of reservoir trapping, water extractions, and floodplain deposition. 
Particulate Nitrogen and Phosphorus budgets are similar to that of TSS. On the other hand, higher percentages of supplied dissolved nutrients and PSII inhibiting herbicides (i.e., 68\% DIN, 67\% DON, 65\% DOP, $67 \%$ DIP and $67 \%$ PSII) are exported to the GBR lagoon, as they are subjected to decay but not to deposition.

Contributions to total export from streambank $(56 \%)$ and hillslope $(28 \%)$ erosion are the dominant sources of TSS export from the region. With a contribution of $67 \%$, streambank erosion is the dominant source of TSS export from the Mary catchment. This result is consistent with previous modelling results (DeRose et al., 2002; Fentie et al., 2006; NLWRA, 2001). However, detailed mapping of streambank migration rates from historic photos in conjunction with sediment tracing studies and establishment of a water quality monitoring site in the Mary catchment will significantly improve confidence in model predictions. Land uses modelled using EMC/DWC values (which, , do not make a distinction between hillslope and gull erosion contributions) accounted for large percentages of the TN (38\%) and TP (37\%) export. It can also be noted that, depending on the constituent of concern, the relative contribution of sources to supply is different to their relative contribution to export to the GBR. This is due primarily to proximity of supply location to export outlet, and the potential for losses to occur during stream transport. For example, hillslope erosion contributes $38 \%$ of total TSS supply but only $28 \%$ of total TSS export. On the other hand, streambank erosion contributes $39 \%$ of total TSS supply but almost $56 \%$ of total TSS export. Gully erosion contributes $17 \%$ of total TSS supply but only $6 \%$ of total TSS export. However, the gully density input layers used in the modelling are based on coarse scale mapping, and future work will endeavour to derive a finer resolution gully map to improve confidence in modelled estimates.

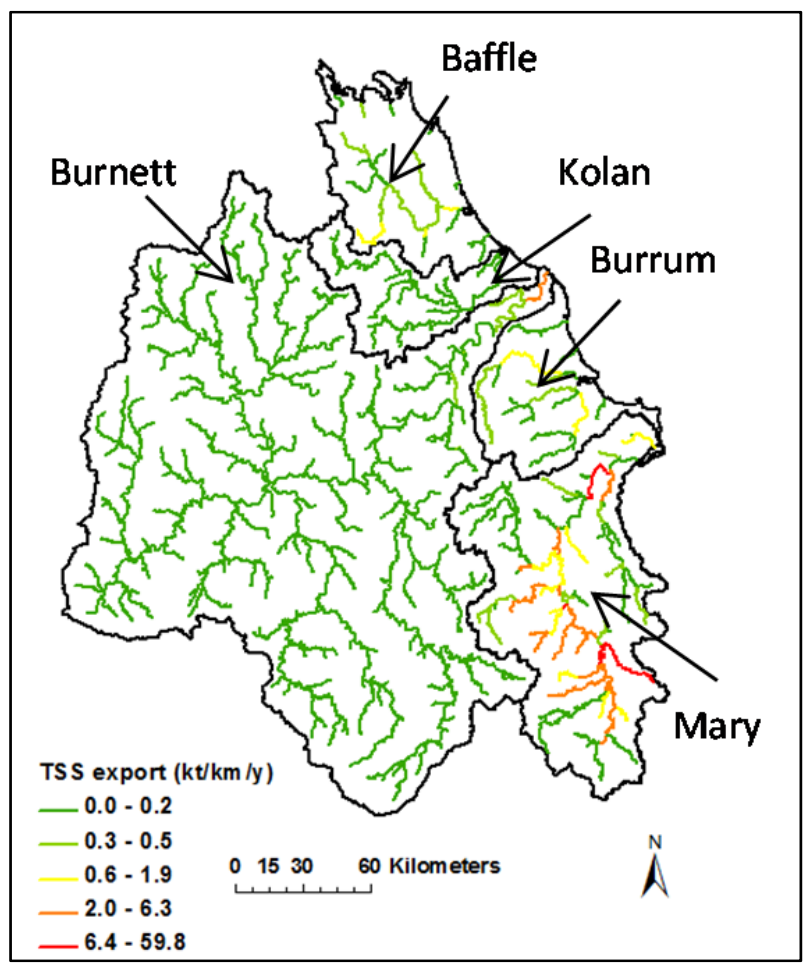

Figure 3. Contribution of streambank erosion to TSS export $(\mathrm{kt} / \mathrm{km} / \mathrm{y})$

Even if a particular source dominates the contribution to constituent export, it should only be targeted for management action if the dominance of its contribution to export is as the result of modifications of the natural environment due to human activity. Modelling of the natural condition (pre-development) scenario in the Burnett Mary has shown that of the $243 \mathrm{kt} / \mathrm{y}$ of TSS exported from the region $85 \%$ is as a result of changes from the natural environment due to human activity. Once sources that dominate constituent export are identified, and if it is determined that most of the contribution from these sources is due to changes in the natural environment as a result of human activity, a map showing the spatial pattern of the extent of the contribution can be used to prioritise locations of on-ground investment in management practice changes. For example, knowing that streambank erosion is the most dominant contributor to suspended sediment export and that most $(85 \%)$ of this contribution is due to changes in the natural environment as a result of human activity, we can produce a map of suspended sediment export per unit stream length, as shown in Figure 3. This map along with ground-truthing and other considerations (e.g., socio-economic factors) can then be used to prioritise funding of riparian re-vegetation or fencing off to restrict stock access. Almost all streams with greater than $2.0 \mathrm{kt} / \mathrm{km} / \mathrm{y}$ contribution to TSS export are in the Mary catchment.

A challenge in using results of the constituent budget modelling presented here is the lack of independent datasets for model validation. However, exports of the major constituents have been compared against loads estimated from monitoring data for four years of monitoring at a gauging station in the Burnett catchment, as shown in Figure 4. The results are encouraging with differences between loads from monitoring (GBRI5 data) and modelling shown in Figure 4 ranging from $6 \%$ for PP to $52 \%$ for DON and $34 \%$ average for all constituents. 


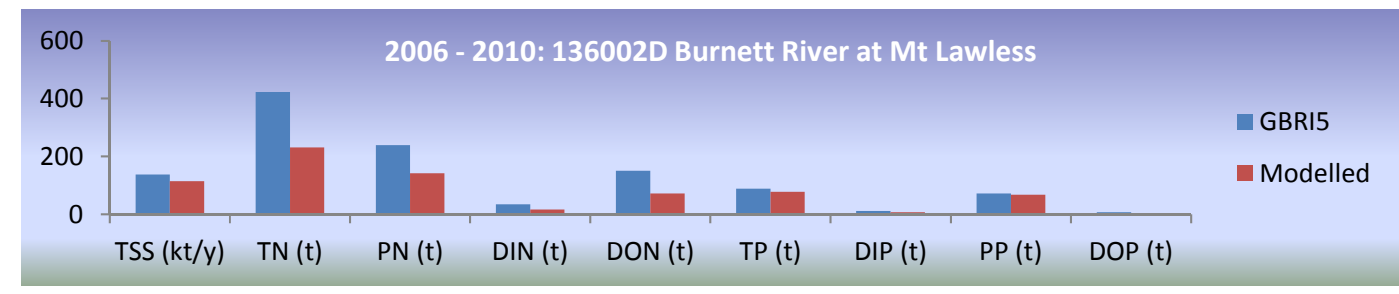

Figure 4. Model validation

\section{CONCLUSIONS AND RECOMMENDATIONS}

The Source Catchment modelling framework incorporating dynamic SedNet provides a very flexible tool to enable detailed spatial and temporal analysis of model outputs. This paper highlights how the model can be used to identify the dominant sources of pollutants from subcatchment to whole of region scale. Comparison of modelled and event monitoring load estimates at an end of catchment site has shown good agreement boosting our confidence in the modelled constituent budget. Major conclusions and recommendations for future work are as follows:

- Given their high percentage contributions, streambank erosion and hillslope erosion should be targeted for on-ground management action in order to achieve maximum reduction in TSS export.

- Whilst agreement with limited available water quality data and with previous modelling estimates indicate that model outputs may be acceptable for the main purpose of this paper, detailed mapping of streambank migration rates from historic photos in conjunction with sediment tracing studies and establishment of a water quality monitoring site in the Mary catchment will significantly improve confidence in model predictions.

- The high sediment loss associated with water extractions need to be verified given that its accuracy has not been tested.

- $\quad$ EMC/DWC based modelling does not make a distinction between gully and hillslope erosion. Future modelling should use a generation model that makes this distinction possible.

- Gully density layers are created based on inadequate data. Future research to address this limitation is recommended.

- The discrepancies between modelled and observed loads for some constituents highlight the need for long term monitoring data at a range of spatio-temporal scales to help refine the model.

\section{ACKNOWLEDGMENTS}

We wish to acknowledge the funding support from the Australian and Queensland governments under the paddock to Reef Program.

\section{REFERENCES}

Accad, A., Neldner, V.J., Wislosn, B.A., Niehus, R.E. (2001). Remnant Vegetation in Queensland: Analysis of Pre-Clearing, Remnant 1997-1999 Regional Ecosystem Information. Queensland Herbarium, Environmental Protection Agency, Brisbane.

Anon (2003). Reef Water Quality Protection Plan. Reef Water Quality Protection Plan: For Catchments Adjacent to the Great Barrier Reef World Heritage Area, 25.

Brodie, J., Waterhouse, J., Schaffelke, B., Kroon, F., Thorburn, P., Rolfe, J., Johnson, J., Fabricius, K., Lewis, S., Warne, M., Mckenzie, L. (2013). 2013 Reef Scientific Consensus Statement, Land use impact of GBR water quality. http://www.reefplan.qld.gov.au/about/assets/scientific-consensus-statement2013.pdf.

Carroll, C., Waters, D., Vardy, S., Silburn, D.M., Attard, S., Thorburn, P.J., Davis, A.M., Halpin, N., Schmidt, M., Wilson, B., Clark, A. (2012). A Paddock to reef monitoring and modelling framework for the Great Barrier reef: Paddock and catchment component. Mar. Pollut. Bull. . 
Fentie et al., Modelling constituent budgets in the Burnett Mary region

Chiew, F.H.S., Peel, M.C., Western, A.W. (2002). Application and testing of the simple rainfall-runoff model SIMHYD, in Singh, V.P., Frevert, D.K. (Eds.), Mathematical Models of Small Watershed Hydrology and Applications. Water Resources Publication, Littleton, Colorado, pp. 335-367.

Department of Premiers and Cabinet (2013). Reef Water Quality Protection Plan, 2013, Securing the health and resilience of the Great Barrier Reef World Heritage Area and adjacent catchments.

Department of Premiers and Cabinet (2009). Reef Water Quality Protection Plan, 2009, For the Great Barrier Reef World Heritage Area and adjacent catchments.

DeRose, R.C., Prosser, I.P., Wilkinson, L.J., Hughes, A.O., Young, W.J. (2002). Regional Patterns of Erosion and Sediment and Nutrient Transport in the Mary River Catchment, Queensland. 37/02, 45-45.

DSITIA (2012). Land use summary 1999 - 2009: Great Barrier Reef catchments.

Ellis, R., Doherty, J., Searle, R. (2009). Applying parameter estimation and prediction uncertainty analysis to WaterCAST water quality models. MODSIM 2009 International Congress on Modeling and Simulation. Modeling and Simulation Society of Australia and New Zealand, Cairns,.

Ellis, R., Searle, R. (2013). An integrated water quality modelling framework for reporting on Great Barrier Reef catchments. MODSIM2013, 20th International Congress on Modelling and Simulation .

eWater Cooperative Research Centre (2010). Source Catchments Scientific Reference Guide, .

Fentie, B., Esslemont, G., Sherman, B.S., Searle, R., Read, A., Chen, Y., Brodie, J., Wilson, P., and Sallaway, M. (2006). Sediment and nutrient modelling in the Burnett Mary NRM region. Volume 6. In: The use of SedNet and ANNEX models to guide GBR catchment sediment and nutrient target setting.

Fentie, B., Pagendam, D., Roberts, D., 2009. Visual comparison of spatial patterns of annual suspended sediment loads estimated by two water quality modelling approaches. 18th World IMACS Congress and MODSIM09 International Congress on Modelling and Simulation: Interfacing Modelling and Simulation with Mathematical and Computational Sciences, Proceedings , 3315-3321.

Keating, B.A., Carberry, P.S., Hammer, G.L., Probert, M.E., Robertson, M.J., Holzworth, D., Huth, N.I., Hargreaves, J.N.G., Meinke, H., Hochman, Z., McLean, G., Verburg, K., Snow, V., Dimes, J.P., Silburn, M., Wang, E., Brown, S., Bristow, K.L., Asseng, S., Chapman, S., McCown, R.L., Freebairn, D.M., Smith, C.J. (2003). An overview of APSIM, a model designed for farming systems simulation. Eur. J. Agron. 18, 267-288.

NLWRA (2001). National Land \& Water Resources Audit - Australian Agriculture Assessment. 1.

Rattray, D.J., Freebairn, D.M., McClymont, D., Silburn, D.M., Owens, J.S., Robinson, J.B. (2004). HOWLEAKY? - the journey to demystifying simple technology. Conserving Soil and Water for Society: Sharing Solutions ISCO 2004, the 13th International Soil Conservation Organisation Conference. Brisbane, July 2004.

Shaw, M., Robinson, J.B., Silburn, D.M., Ellis, R., Searle, R. (2012). Paddock to Reef Integrated Monitoring, Modelling and Reporting Program, Paddock Scale Modelling Technical Report.

Waterhouse, J., Brodie, J., Lewis, S., Mitchell, A. (2012). Quantifying the sources of pollutants in the Great Barrier Reef catchments and the relative risk to reef ecosystems. Mar. Pollut. Bull. 65, 394-406.

Wilkinson, S., Henderson, A., Chen, Y. (2004). SedNet user guide, version 2. Canberra: CSIRO Land and Water. 